Yong Pan, Junwei Cui, Weixin Lei, Jie Zhou and Zengsheng Ma*

\title{
Influence of Heat Treatment on the Mechanical Properties of Ni Films on 430 Stainless Steel Substrate
}

DOI 10.1515/htmp-2016-0025

Received February 1, 2016; accepted June 16, 2016

\begin{abstract}
Effects of heat treatment on the mechanical properties of Ni films on 430 stainless steel substrate were investigated. The $\mathrm{Ni}$ films were annealed at heat treatment temperatures ranging from $0^{\circ} \mathrm{C}$ to $800^{\circ} \mathrm{C}$ for $2 \mathrm{~h}$. The surface morphology, composition, and texture orientation of Ni films were studied by scanning electron microscopy, energy dispersive spectrometry, and $\mathrm{X}$-ray diffraction. The load-indentation depth curves of $\mathrm{Ni}$ films before and after heat treatment were measured by using nanoindentation method. In conjunction with finite element modeling and dimensional analysis, the stress-strain relationships of Ni films on 430 stainless steel substrate at different temperatures are successfully obtained by using a power-law hardening model.
\end{abstract}

Keywords: heat treatment, nanoindentation, Ni films, stress-strain relationship

\section{Introduction}

With the development of metal film preparation technology, the pulse electro-deposition, as a simple, highly active, and low-cost deposition method, had been used to deposit nanocrystalline films [1]. With respect to the deposition of nanocrystalline film, the pulse electrodeposition had been extensively used to improve the hardness, wear, and corrosion resistance of electroplated metal films [1, 2].

*Corresponding author: Zengsheng Ma, National - Provincial Laboratory of Special Function Thin Film Materials, and School of Materials Science and Engineering, Xiangtan University, Hunan 411105, China, E-mail: zsma@xtu.edu.cn

Yong Pan, Junwei Cui, Weixin Lei, Jie Zhou, National - Provincial Laboratory of Special Function Thin Film Materials, and School of Materials Science and Engineering, Xiangtan University, Hunan 411105, China
Heat treatment was widely used on 304 stainless steel [3], aluminum alloy [4], and nickel films [5] in order to improve their machining properties for eliminating alloy imbalance phase and over saturation [6] as well as reducing surface cracks, and enhancing adhesion strength of film to substrate [7]. Therefore, it is essential to assess the mechanical properties of Ni films on 430 stainless steel substrate at different temperatures, especially their stress-strain relationships. In comparison to traditional methods, nanoindentation is a convenient, nondestructive method, which has been widely used to measure mechanical properties of small samples, such as hardness, Young's modulus, yield strength, hardening exponent, etc. [8-10]. The load-indentation depth relationship of an elastic-plastic material was supposed to be a linear combination of elastic and elastic-perfectly plastic response, and then an optimization method was introduced in reverse analysis [11]. In the work of Dao et al. [12], a computational study was undertaken to identify the extent to which the elastoplastic properties of ductile materials could be determined by instrumented sharp indentation and to quantify their sensitivity to variations of indentation data. They concluded that the unique properties can be obtained by a sharp indentation curve. We also proposed an inverse method for extracting the elastic-plastic properties of metallic thin films from instrumented sharp indentation in terms of dimensional analysis and finite element modeling [13, 14]. A wide range of materials with different elastic modulus, yield strength, and strain-hardening exponent were examined.

In this paper, the surface morphology, composition, and texture orientation of Ni films on 430 stainless steel substrate at different temperatures were studied by scanning electron microscopy (SEM), energy dispersive spectrometry (EDS) and X-ray diffraction (XRD). The loadindentation depth curves of Ni coatings before and after heat treatment were measured using nanoindentation method. In conjunction with finite element modeling and dimensional analysis, we aim to characterize the stress-strain relationships of $\mathrm{Ni}$ films on 430 stainless steel substrate at different temperatures by using a power-law hardening model. 


\section{Experimental}

\section{Samples and heat treatment}

A $0.3-\mathrm{mm}$ thick 430 stainless steel sheet was used as the substrate. A uniform nickel film of 3,000 nm thick was prepared by electrodeposition on both sides of the steel sheet. The film was obtained with nickel sulfate electrolyte, which was composed of $250 \mathrm{~g}$ of $\mathrm{NiSO}_{4} \cdot 6 \mathrm{H}_{2} \mathrm{O}, 50 \mathrm{~g}$ of $\mathrm{NiCl}_{2} \cdot 6 \mathrm{H}_{2} \mathrm{O}$ and $35 \mathrm{~g}$ of $\mathrm{H}_{3} \mathrm{BO}_{3}$ per liter. Pure nickel was used as the anode. The $\mathrm{pH}$ value was adjusted with sulfuric acid to 4.0 at $42^{\circ} \mathrm{C}$. A conventional rotating disc electrode was used for electrodeposition. Before electroplating, pretreatments were necessary to get rid of the impurities. Then the samples were heated for $2 \mathrm{~h}$ at the temperature of $400,500,600,700$, and $800^{\circ} \mathrm{C}$ in argon protective atmosphere with a purity of $99.9 \%$. Then the samples were cooled down in the protect atmosphere until room temperature.

The morphology of Ni films on 430 stainless steel substrate at different temperatures was observed by SEM (JMS-5600LV SEM). The chemical composition was studied by the EDS (QUANTA200). The Rigaku D/MAX2500 X-ray diffusion detector (XRD) was used to calculate the average grain sizes and the texture density of the samples.

\section{Nanoindentation}

Nanoindentation tests were conducted by using a Tribo Indenter (Hysitron Inc.) with a three-sided pyramidal Berkovich diamond indenter. Its load and displacement resolutions are $100 \mathrm{nN}$ and $0.1 \mathrm{~nm}$, respectively. Ni films were tested by the maximum load $F=1,000 \mu \mathrm{N}$ with the loading and unloading rate $\mathrm{d} P / \mathrm{d} t=200 \mu \mathrm{N} / \mathrm{s}$ and the holding time $T=5 \mathrm{~s}$. In all cases, at least five tests were repeated at a given load to obtain load-indentation depth curves.

\section{Theoretical framework}

\section{Material model}

For elastic-plastic material, its load-displacement curve is illustrated in Figure 1(a). To improve the accuracy and comparability of hardness and modulus results from nanoindentation experiments, an evaluation of the creep behavior is required. Creep depends on the material and normally diminishes to very low values within some seconds. Nevertheless, it influences the maximum depth and the upper part of the unloading curve in a way that measurement errors of more than $20 \%$ may occur [15]. Hold periods are proposed in dependence on the material type that should be kept for high accuracy measurements. Feng and Ngan solved the problem of indentation on a linear viscoelastic half-space using the correspondence principle between elasticity and linear viscoelasticity [16]. The correction term due to creep in the apparent contact compliance is found to be equal to the ratio of the indenter displacement rate at the end of the load hold to the unloading rate. According to Kick's law [17], a natural outcome during loading with a Berkovich indenter can be represented as

$$
P=C h^{2}
$$

where $P$ is the indentation load, $h$ is the indentation depth, and the loading curvature $C$ is a material constant.

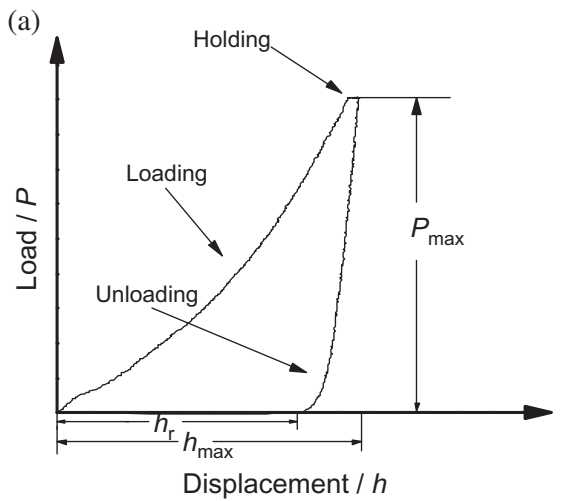

(b)

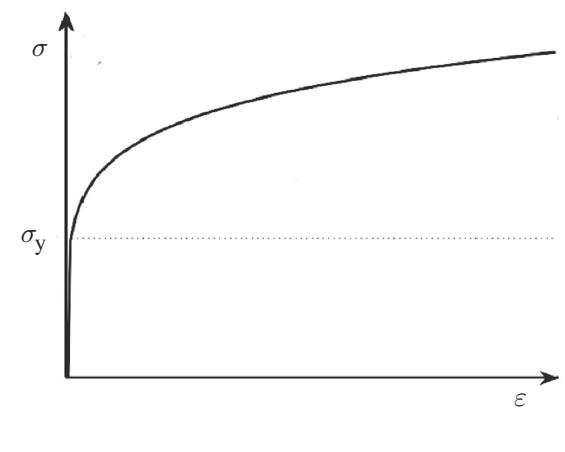

Figure 1: (a) Schematic representation of a load-displacement curve in indentation and (b) the power-law elastic-plastic stress-strain behavior. 
As shown in Figure 1(b), for the plastic deformation of metals, a power-law work-hardening law is a fairly good approximation and its corresponding stress-strain curve under uniaxial tension is given by

$$
\varepsilon= \begin{cases}\frac{\sigma}{E}, & \sigma \leq \sigma_{\mathrm{y}} \\ \frac{\sigma_{\mathrm{y}}}{E}\left(\frac{\sigma}{\sigma_{\mathrm{y}}}\right)^{(1 / n)}, & \sigma>\sigma_{\mathrm{y}}\end{cases}
$$

It is obvious that there are three parameters, i. e. elastic modulus $E$, initial yield strength $\sigma_{\mathrm{y}}$, and work hardening exponent $n . \sigma_{\mathrm{y}}$ is the initial yield stress at zero offset strain [18]. Thus, the three parameters (i. e., $E, n$, and $\left.\sigma_{\mathrm{y}}\right)$ are essential to determine the stress-strain curve.

\section{Dimensional analysis}

Let us consider an ideal situation of a rigid indenter acting on a smooth surface. Here, the force $(F)$ on the indenter and the contact depth $\left(h_{\mathrm{c}}\right)$ are chosen as dependent variables, and thus, the indentation depth $h$ is an independent variable. Other independent parameters include the indenter half-angle $\theta$ and the friction coefficient $\mu$ between the indenter and material [19]. The two dependent variables can be written as

$$
\begin{gathered}
F=F\left(h, E, \nu, E_{i}, v_{i}, \sigma_{\mathrm{y}}, n, \mu, \theta\right) \\
h_{c}=h_{c}\left(h, E, v, E_{i}, v_{i}, \sigma_{\mathrm{y}}, n, \mu, \theta\right)
\end{gathered}
$$

where $E$ and $v$ are the elastic modulus and Poisson's ratio of the material (indenter), respectively. Taking the small deformation of a diamond indenter into account, $E_{i}, v_{i}$, and $\mu$ can be ignored in eq. (3). As is well known, Poisson's ratio of metal materials is about $0.3[20,21]$. Thus, for a given indenter with the angle $\theta$, eq. (3) can be simplified as

$$
\begin{gathered}
F=F\left(h, E, \sigma_{\mathrm{y}}, n\right) \\
h_{\mathrm{c}}=h_{\mathrm{c}}\left(h, E, \sigma_{\mathrm{y}}, n\right)
\end{gathered}
$$

Now, we choose $E$ and $h$ as basic physical quantities, and then we have

$$
\begin{gathered}
{[F]=[E][h]^{2}} \\
{\left[\sigma_{\mathrm{y}}\right]=[E]} \\
{[n]=[E]^{0}[h]^{0}} \\
{\left[h_{\mathrm{c}}\right]=[E]^{0}[h]^{1}}
\end{gathered}
$$

According to the ח-theorem of dimensional analysis, two nondimensional functions can be obtained as

$$
\begin{aligned}
\frac{F}{E h^{2}} & =\Pi_{\alpha}\left(\frac{\sigma_{\mathrm{y}}}{E}, n\right) \\
\frac{h_{\mathrm{c}}}{h} & =\Pi_{\beta}\left(\frac{\sigma_{\mathrm{y}}}{E}, n\right)
\end{aligned}
$$

\section{Elastic modulus}

Next, the effective elastic modulus $E_{r}$ and the unloading stiffness $S$ (the slope of the unloading curve in Figure 1(a) are defined as

$$
S=\frac{2}{\sqrt{\pi}} E_{r} \sqrt{A}
$$

Hence,

$$
E_{r}=\frac{\sqrt{\pi}}{2} \cdot \frac{S}{\sqrt{A}}
$$

where the projected contact area $A$ of impression can be derived by an empirical shape function at the contact depth $h_{\mathrm{c}}$ [22] for conical, cylindrical, spherical, and flat indenters [23]. Furthermore, eqs. (7) and (8) can be rewritten as

$$
S=\frac{2}{\sqrt{\pi}} \beta E_{r} \sqrt{A}
$$

Then,

$$
E_{r}=\frac{\sqrt{\pi}}{2 \beta} \cdot \frac{S}{\sqrt{A}}
$$

where $\beta$ is equal to 1.14 and 1.058 for Berkovich and conical indenters, respectively [24]. Once the equivalent elastic modulus is determined by [25]

$$
\frac{1}{E_{r}}=\frac{1-v^{2}}{E}+\frac{1-v_{i}^{2}}{E_{i}}
$$

The elastic modulus $E$ (neglecting deformation of diamond indenter) can be obtained as

$$
E=\left(1-v^{2}\right) E_{r}
$$

\section{Positive and reverse analyses}

As illustrated in Figure 2, there are two steps in either the positive analysis or the reverse analysis [25]. During the positive analysis, finite element calculations are first carried out to obtain several groups of load-displacement curves (defined by $F, h, S$, and $h_{\mathrm{c}}$ ) for given material combinations (defined by $E, \sigma_{\mathrm{y}}$, and $n$ ). Then, dimensionless functions $\left(\Pi_{\alpha}\right.$ and $\Pi_{\beta}$ ) are determined through numerical fitting to discrete 


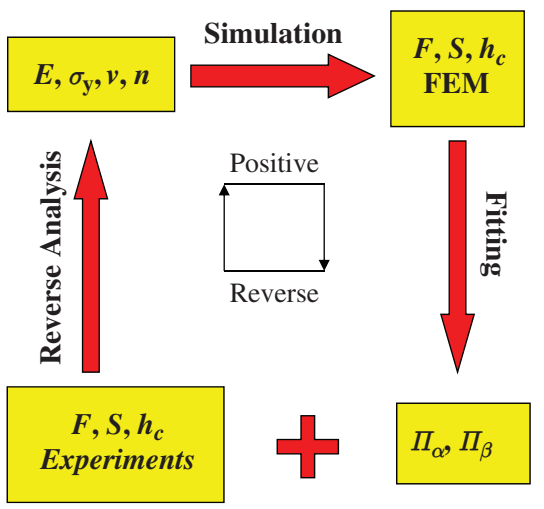

Figure 2: Flowchart for extracting the plastic properties of materials from the sharp indentation-loading curve by using positive and reverse analyses.

points with proper functions. During the reverse analysis, the load-displacement curve is obtained by nanoindentation tests. Then, $\Pi_{\alpha}$ and $\Pi_{\beta}$ can be calculated by indentation information (i.e. $F, h$, and $h_{\mathrm{c}}$ ). Following the positive and revise analyses [13], $\sigma_{\mathrm{y}}$ and $n$ can be extracted from the dimensionless functions in

$$
\begin{aligned}
\Pi_{\alpha}\left(\frac{\sigma_{\mathrm{y}}}{E}, n\right) & =(2.77-2.11 n)\left(\frac{\sigma_{\mathrm{y}}}{E}\right)^{-0.064 \ln \left(\sigma_{\mathrm{y}} / E\right)-0.42 n} \\
\pi_{\beta}\left(\frac{\sigma_{\mathrm{y}}}{E}, n\right) & =0.70+0.55 \exp (-2.16 n) \cdot \exp \left(-40.32 \frac{\sigma_{\mathrm{y}}}{E}\right)
\end{aligned}
$$

Because of the scale effect and the bonding strength, it is very difficult to obtain the mechanical properties of thin films directly. Here, we present the reverse analyses method to characterize the stress-strain relationships of Ni films by nanoindentation.

\section{Results and discussion}

Figure 3 shows SEM images and EDS analyses of Ni films on 430 stainless steel substrate at different heat treatment temperatures, where the inset is the corresponding SEM images of cross section. For the as-deposited Ni films, a very smooth surface can be obtained with a grain size of $40 \mathrm{~nm}$ in Figure 3(a). In the inset, it is clear that the thickness of $\mathrm{Ni}$ film is about 3,000 $\mathrm{nm}$. With the increase of heat treatment temperature, the grain becomes bigger, as shown in Figure 3(b) and (c). The grain size increases to $\sim 1 \mu \mathrm{m}$ for the heat treatment temperature of $800^{\circ} \mathrm{C}$. The EDS analysis of the cross section at $600^{\circ} \mathrm{C}$ indicates that the $\mathrm{Ni}$ film/Fe substrate system is mainly composed of $\mathrm{Ni}$ and Fe species, as shown in Figure 3(d). It is clearly seen that the content of iron is less than $\mathrm{Ni}$ in the film though some iron atoms have diffused into the Ni film. Diffusion interface moved because the elements in the film and substrate diffuse to each other during heat treatment, and the interface moves toward the $\mathrm{Ni}$ film
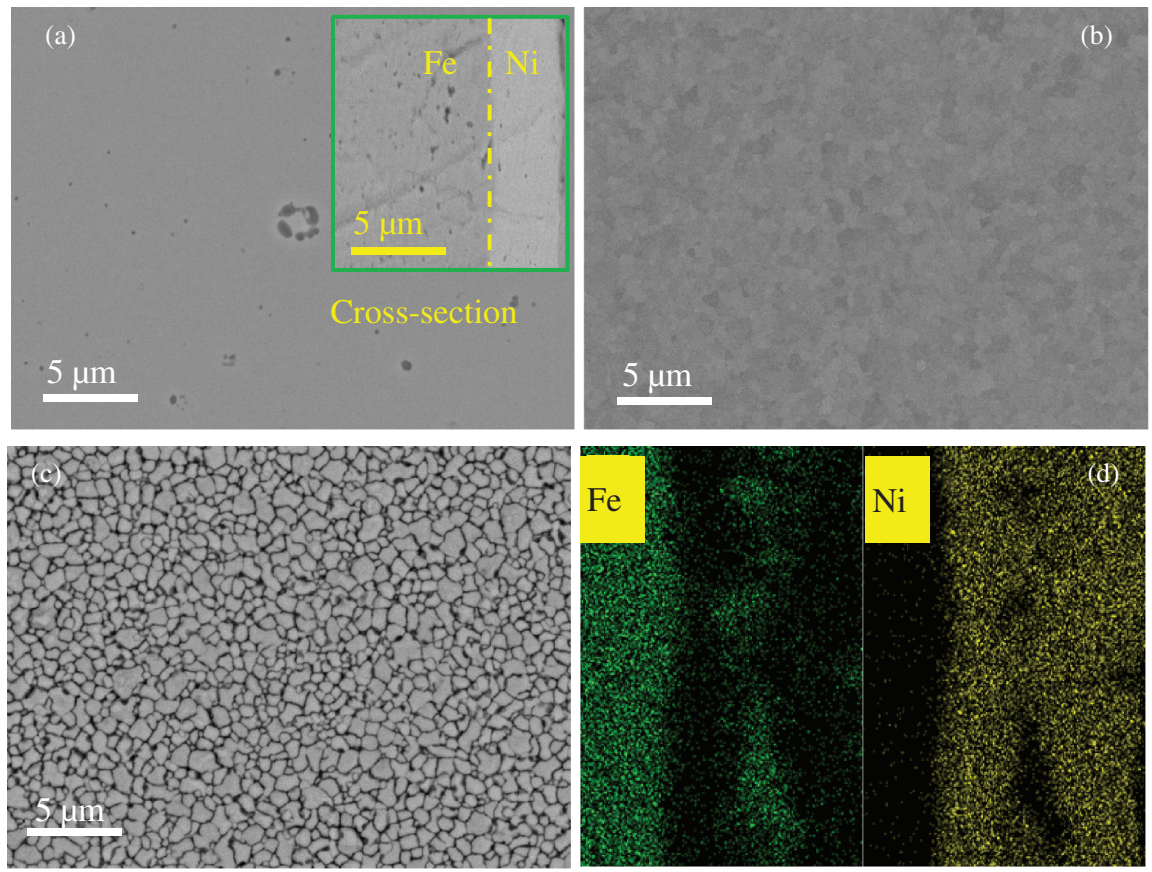

Figure 3: SEM image of $\mathrm{Ni}$ films on 430 stainless steel substrate at different heat treatment temperatures: (a) As-deposited, (b) $500^{\circ} \mathrm{C}$, (c) $700^{\circ} \mathrm{C}$, and (d) EDS of section pattern for Fe and Ni elements at $600^{\circ} \mathrm{C}$. 


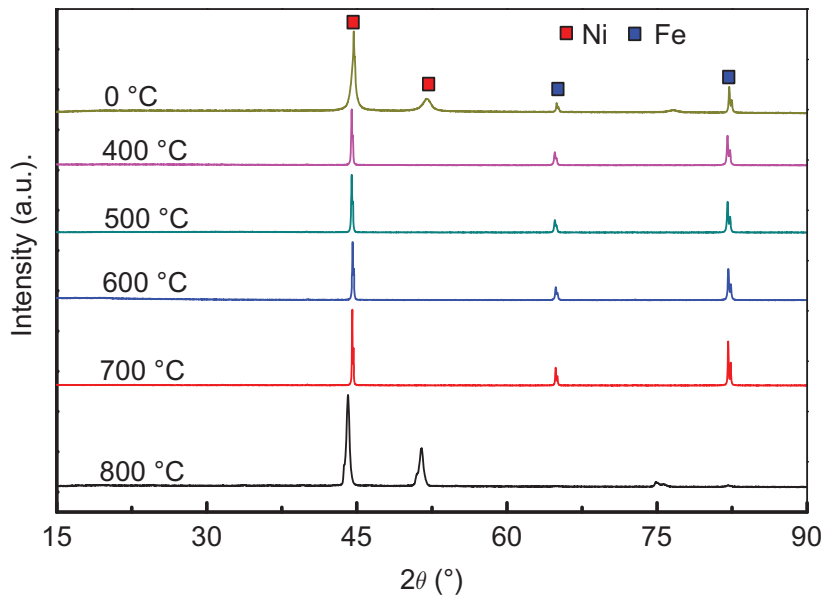

Figure 4: XRD patterns of Ni films on 430 stainless steel substrate at different heat treatment temperatures.

with a higher diffusion rate, which matches well with the Kirkendall effect [26].

Texture directions of Ni films on 430 stainless steel substrate at different heat treatment temperatures ranging from $0^{\circ} \mathrm{C}$ to $800^{\circ} \mathrm{C}$ are examined by XRD in Figure 4. It is found that the structures of the Ni films exhibit a preference of the (1 1111$)$ and (2 000$)$ orientations. With increasing the heat treatment temperatures, the texture directions change slightly, which indicates that no second phase appears. However, the diffraction peaks shift left gradually with increasing heat treatment temperature, implying the formation of new solid solutions.

Figure 5 shows the load-displacement curves with the maximum load of $1,000 \mu \mathrm{N}$ for the Ni films at different heat treatment temperatures ranging from $0^{\circ} \mathrm{C}$ to $800^{\circ} \mathrm{C}$. It is found that for a given value of $1,000 \mu \mathrm{N}$, the maximum

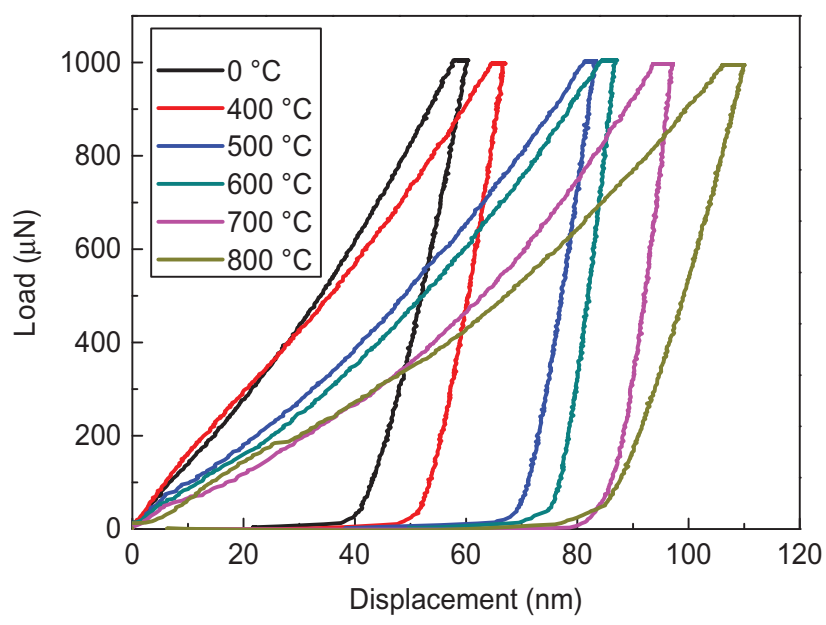

Figure 5: The load-indentation depth curves of $\mathrm{Ni}$ films on 430 stainless steel substrate at different heat treatment temperatures. penetration depth increases from $60 \mathrm{~nm}$ to $110 \mathrm{~nm}$ with increasing heat treatment temperatures from $0{ }^{\circ} \mathrm{C}$ to $800^{\circ} \mathrm{C}$. This indicates a softening effect of $\mathrm{Ni}$ films due to the heat treatment process. The indentation creep displacement is about $5 \mathrm{~nm}$, which agrees well with previous results [27-29]. For consistency, only load-displacement profiles that mapped onto the same master curve were admitted as valid measurements (the invalid profiles have a fraction less than $5 \%$ for each film we tested).

The influence of the heat treatment temperatures on the measured elastic modulus and hardness values for $\mathrm{Ni}$ films is shown in Figure 6(a) and (b), respectively. Both, the elastic modulus and hardness show a strong heat treatment temperature effect with the apparent elastic modulus and hardness decreasing with increasing heat treatment temperatures. For low heat treatment temperatures, the elastic modules are about $160 \mathrm{GPa}$ which is insignificant to the temperatures. However, the heat treatment temperature increases to $800^{\circ} \mathrm{C}$, the elastic modulus value decreases to $70 \mathrm{GPa}$ suddenly, as shown in Figure 6(a). In addition, the hardness value decreases from $7.5 \mathrm{GPa}$ to $3 \mathrm{GPa}$ with the increasing heat treatment temperatures from $0^{\circ} \mathrm{C}$ to $800^{\circ} \mathrm{C}$ in Figure $6(\mathrm{~b})$. This can be attributed to the increasing grain size due to heat treatment. The smaller the grain size, the stronger the strength, which agrees well with Hall-Petch effect [30]. Furthermore, according to the investigations by Buchheit et al. [31], the evolution of microstructure in the annealed $\mathrm{Ni}$ materials corresponded with a dramatic drop in their strength and determined the limiting diffusion-bonding temperature. Significant strength decreases occurred during heat treatments at temperatures greater than $400^{\circ} \mathrm{C}$, corresponding to recrystallization and rapid grain growth of the recrystallized microstructure.

According to the reverse analysis, the mechanical properties $\left(E, \sigma_{\mathrm{y}}\right.$, and $\left.n\right)$ can be derived from the measured load-displacement curves and their corresponding data (see Table 1). Then, the stress-strain curves are described at different heat treatment temperatures ranging from $0{ }^{\circ} \mathrm{C}$ to $800^{\circ} \mathrm{C}$. As shown in Figure 7, the yield strength and elastic modulus decrease with the increase of heat treatment temperature. From Table 1, it can be seen that the elastic modulus decreases from $148 \mathrm{GPa}$ $\left(0^{\circ} \mathrm{C}\right)$ to $69 \mathrm{GPa}\left(800^{\circ} \mathrm{C}\right)$. There is a similar tendency for the decrease of yield strength with the increase of heat treatment temperature. In the case of $0^{\circ} \mathrm{C}$, yield strength is $1.79 \mathrm{GPa}$. With the increase of heat treatment temperature to $800^{\circ} \mathrm{C}$, yield strength gradually decreases to $\sim 400$ MPa. In addition, it is worth noting that, as shown in Table 1, there is a slight change of the $n$ values around 0.4 with the increase of heat treatment temperature. 

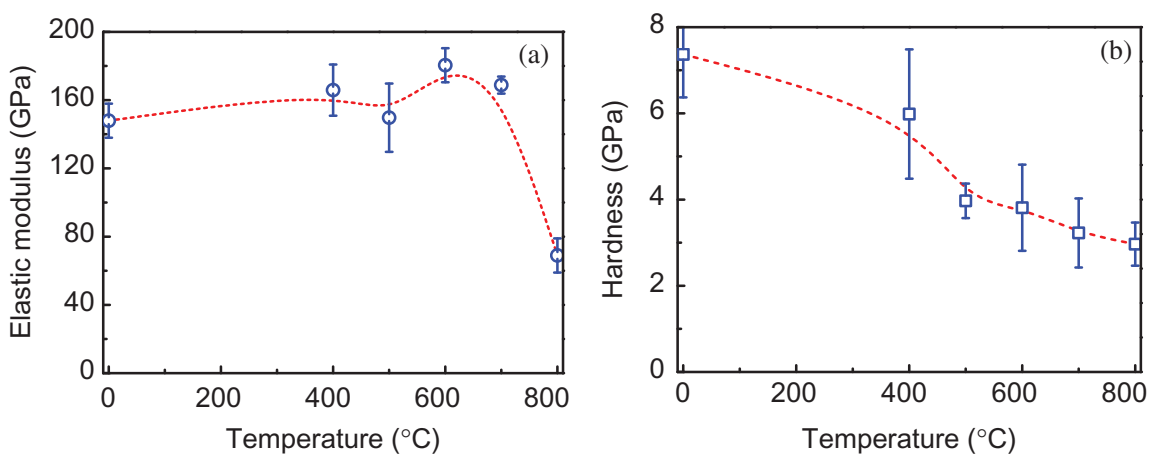

Figure 6: Temperature dependence of (a) elastic modulus and (b) hardness.

Table 1: Mechanical properties of Ni films at different heat treatment temperatures.

\begin{tabular}{lrrr}
\hline Heat treatment temperature $\left({ }^{\circ} \mathrm{C}\right)$ & $E(\mathrm{GPa})$ & $\sigma_{\mathrm{y}}(\mathrm{GPa})$ & $\boldsymbol{n}$ \\
\hline 0 & 147.95 & 1.79 & 0.538 \\
400 & 165.86 & 1.01 & 0.469 \\
500 & 149.71 & 0.47 & 0.414 \\
600 & 180.46 & 0.41 & 0.392 \\
700 & 168.84 & 0.31 & 0.379 \\
800 & 68.94 & 0.40 & 0.465 \\
\hline
\end{tabular}

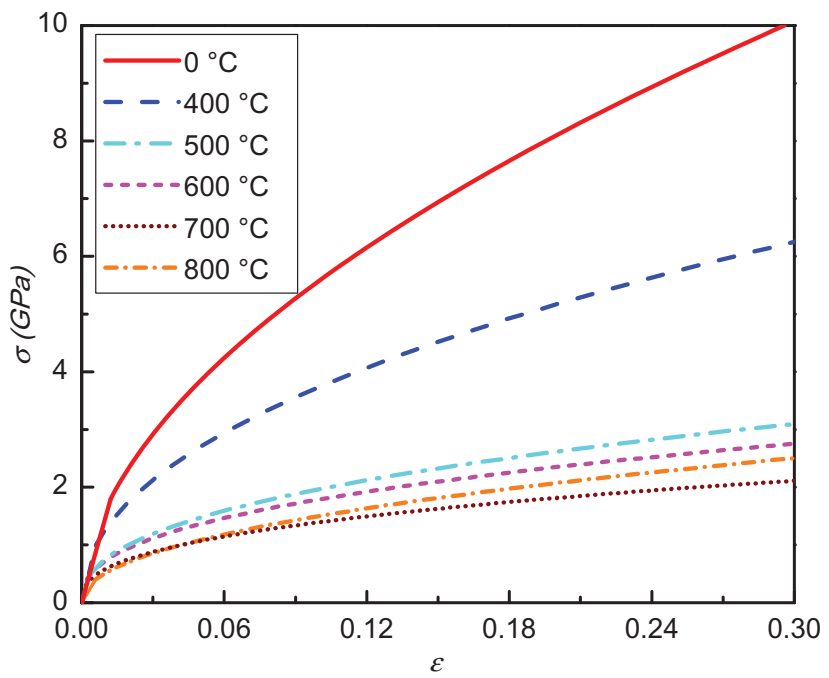

Figure 7: The stress-strain relationships of $\mathrm{Ni}$ films on 430 stainless steel substrate at different temperatures.

\section{Conclusion}

In this paper, the Ni films on 430 stainless steel substrate systems are prepared by pulse electrodeposition at different heat treated temperatures ranging from $0^{\circ} \mathrm{C}$ to $800^{\circ} \mathrm{C}$.
Using a combination of dimensional analysis and finite element modeling, we extracted successfully the elasticplastic properties of $\mathrm{Ni}$ films at different heat treatment temperatures by an inverse method. The results shown that, with the increase of heat treatment temperatures, the elastic modulus and yield strength obviously decrease. It is expected that this study can be used in the characterization of mechanical properties for metallic films at the heat treatment processes.

Funding: This work was supported by the National Natural Science Foundation of China (Grant No.11372267), and the National High Technology Research and Development Program of China (863 Program) (Grant No. 2013AA032502).

\section{References}

[1] N. Qu, D. Zhu, K. Chan and W. Lei, Surf. Coat. Technol., 168 (2003) 123-128.

[2] T. Xu and W. Lee, J. Mater. Process. Technol., 69 (1997) 90-94.

[3] H. Ataee-Esfahani, M. Vaezi, L. Nikzad, B. Yazdani and S. Sadrnezhaad, J. Alloys Compd., 484 (2009) 540-544.

[4] R. Mahmudi, J. Mater. Process. Technol., 82 (1998) 46-52.

[5] Y. Yin, R.M. Rioux, C.K. Erdonmez, S. Hughes, G.A. Somorjai and A.P. Alivisatos, Science, 304 (2004) 711-714.

[6] S. Wang, Thin Solid Films, 515 (2007) 8419-8423.

[7] J. Lee, D. Ko, K. Lee and B. Kim, J. Mater. Process. Technol., 187 (2007) 309-313.

[8] Y. Liu, B. Wang, M. Yoshino, S. Roy, H. Lu and R. Komanduri, J. Mech. Phys. Solids, 53 (2005) 2718-2741.

[9] A. Elmustafa and D. Stone, J. Mech. Phys. Solids, 51 (2003) 357-381.

[10] S. Qu, Y. Huang, G. Pharr and K. Hwang, Int. J. Plast., 22 (2006) 1265-1286.

[11] Y.T. Cheng and C.M. Cheng, J. Mater. Res., 14 (1999) 3493-3496.

[12] M. Dao, N. Chollacoop, K.J. Van Vliet, T.A. Venkatesh and S. Suresh, Acta Mater., 49 (2001) 3899-3918.

[13] Z.S. Ma, Y.C. Zhou, S.G. Long and C.S. Lu, J. Mater. Sci. Technol., 28 (2012) 626-635. 
[14] Z. Ma, Y. Zhou, S. Long, X. Zhong and C. Lu, Mech. Mater., 54 (2012) 113-123.

[15] T. Chudoba and F. Richter, Surf. Coat. Technol., 148 (2001) 191-198.

[16] G. Feng and A.H.W. Ngan, J. Mater. Res., 17 (2002) 660-668.

[17] J.L. Bucaille, S. Stauss, E. Felder and J. Michler, Acta Mater., 51 (2003) 1663-1678.

[18] Z. Ma, Y. Zhou, S. Long and C. Lu, Int. J. Plast., 34 (2012) 1-11.

[19] Z. Ma, Y. Zhou, S. Long and C. Lu, Surf. Coat. Technol., 207 (2012) 305-309.

[20] K. Tunvisut, N.P. O'Dowd and E.P. Busso, Int. J. Solids Struct., 38 (2001) 335-351.

[21] J. Luo and J. Lin, Int. J. Solids Struct., 44 (2007) 5803-5817.

[22] X. Deng, N. Chawla, K. Chawla and M. Koopman, Acta Mater., 52 (2004) 4291-4303.

[23] W.C. Oliver and G.M. Pharr, J. Mater. Res., 7 (1992) 1564-1583.
[24] P.L. Larsson, A. Giannakopoulos, E. Söderlund, D. Rowcliffe and R. Vestergaard, Int. J. Solids Struct., 33 (1996) 221-248.

[25] D. Joslin and W. Oliver, J. Mater. Res., 5 (1990) 123-126.

[26] E. Kirkendall and A. Smigelskas, Trans. AIME, 171 (1947) 130-142.

[27] Z.S. Ma, S.G. Long, Y.C. Zhou and Y. Pan, Scripta Mater., 59 (2008) 195-198.

[28] Z. Ma, S. Long, Y. Pan and Y. Zhou, J. Mater. Sci. Technol., 25 (2009) 90-94.

[29] Z. Ma, S. Long, Y. Pan and Y. Zhou, J. Mater. Sci., 43 (2008) 5952-5955.

[30] Y. Cao, S. Allameh, D. Nankivil, S. Sethiaraj, T. Otiti and W. Soboyejo, Mater. Sci. Eng. A, 427 (2006) 232-240.

[31] T.E. Buchheit, J.R. Michael, T.R. Christenson, D.A. LaVan and S.D. Leith, Metall. Mater. Trans. A, 33 (2002) 539-554. 